\title{
RELATIONSHIP OF NURSE SERVICE QUALITY WITH PATIENT SATISFACTION IN IN PATIENTROOMS GRANDMED HOSPITAL
}

\author{
Tati Murni Karokaro', Rawaty Sitorus ${ }^{2}$, Peni Rio Ginting ${ }^{3}$, \\ Abdi Lestari Sitepu ${ }^{4}$, Safril Matua Harahap ${ }^{5}$
}

Institut Kesehatan Medistra Lubuk Pakam

Fakultas Keperawatan Dan Fisioterapi, Program Studi Keperawatan S1

Jl. Sudirman No. 38 Lubuk Pakam, Kab. Deli Serdang

E-mail: tatikarokaro612sp@gmail.com

\begin{abstract}
Hospital is a health service that has permanent facilities and infrastructure consisting of professional medical personnel to provide health services, continuous nursing care, and diagnose and provide disease treatment to patients in need. The hospital must fulfill superior facilities, have professional human resources, all of which are part of influencing services to provide satisfaction to patients. This study aims to determine the relationship between the quality of nurse services and patient satisfaction in the inpatient room of the GrandMed Hospital, using a descriptive survey research type. The sample of this study was 27 patients in the Ns 4D room using a questionnaire instrument. The sampling technique used was purposive sampling. The results of the research obtained are those who have good quality nurse service 16 people (59.3\%) and bad service quality 11 people $(40.7 \%), 17$ people who are satisfied $(63.0 \%)$ and dissatisfied as many 10 people $(37.0 \%)$, so that the results of the chi square statistical test obtained $p$ value $=0.021$, which means that there is a relationship between the quality of nurse services and satisfaction in the 4D patient room of Grandmed Hospital. From the results of this study, the advice that I can give is that nurse can apply the results of this research and make it into consideration for improving nursing services at the hospital not only in the 4D patient room but to all inpatient rooms at GrangMed Hospital. This research can be examined again with a larger number of samples and a larger number of rooms or hospitals in order to see more broadly about the effect of nursing services on patient satisfaction.
\end{abstract}

Key words : Quality Services, Satisfaction and Nursing 


\section{PENDAHULUAN}

Rumah sakit merupakan pelayanan kesehatan yang memiliki sarana dan prasarana yang permanen yang terdiri dari tenaga medis yang profesional untuk menyelenggarakan pelayanan kesehatan, asuhan keperawatan yang berkesinambungan, dan mendiagnosis serta memberikan pengobatan penyakit kepada pasien yang memerlukan. Rumah sakit harus memenuhi kelengkapan fasilitas yang unggul, memiliki sumber daya manusia yang profesional, dimana semua itu merupakan bagian yang mempengaruhi pelayanan untuk memberikan kepuasan kepada pasien (Salimah, 2016).

Standar kepuasan pasien ditetapkan oleh Departemen Kesehatan. Berdasarkan Peraturan Kemenkes Tahun 2016 tentang Standar Pelayanan Minimal kepuasan pasien harus melebihi dari 95\%, namun bila ditemukan pelayanan kesehatan dengan tingkat kepuasaan pasien dibawah 95\% (Kemenkes, 2016).

Penelitian yang dilakukan di Kota Kenya pada tahun 2017 oleh Ndambuki diperoleh hasil tingkat kepuasan pasien $40,4 \%$, sedangkan hasil penelitian Twayana di kota Bakhtapur negara India didapatkan kepuasan psien yaitu $34,4 \%$, sedangkan di Indonesia angka kepuasaan pasien 42,8\%, (Latupono, 2017; Sari, 2017).

Berdasarkan data diatas maka dapat di ambil kesimpulan bahwa angka kepuasaan pasien didapat rendah, sehingga kepuasaan pasien akan menjadi masalah di Indonesia dan dunia. Rendahnya angka persentase kepuasan pasien sangat mempengaruhi perkembangan rumah sakit. Hal ini dapat mengakibatkan kurangnya kunjungan pasien karena pelayanan yang mereka dapatkan tidak dapat memuaskan sehingga pasien memutuskan untuk mencari pelayanan keperawatan yang lebih baik (Kotler, 2015 \& Barata 2015).

Penelitian Irmawati tahun 2017 menunjukkan bahwa keputusan pasien untuk menggunakan pelayanan kesehatan dipengaruhi oleh faktor kualitas pelayanan rumah sakit. Oleh karena itu kepuasan pasien yang kurang dapat mengakibatkan kurangnya kepercayaan masyarakat terhadap rumah sakit tersebut.

Perawat adalah tenaga kesehatan yang profesional yang menjadi ujung tombak dalam memberikan pelayanan keperawatan dirumah sakit. Perawat memiliki peranan penting dalam memberikan asuhan keperawatan dengan kualitas yang tinggi karena perawat berinteraksi langsung dengan pasien selama 24 jam (Nursalam, 2016).

Oleh karena itu pelayanan keperawatan memiliki peranan yang besar dalam meningkatkan mutu pelayanan kesehatan rumah sakit. Pelayanan yang berkualitas merupakan salah satu bagian dalam menentukan kepuasan pasien dirumah sakit. Pelayanan keperawatan diharapkan dapat menjadi pelayanan yang professional sesuai dengan standar pelayanan yang dapat memberikan rasa nyaman kepada pasien pasien (Nursalam, 2016).

Ukuran yang dapat di gunakan sebagai alat untuk mengukur kepuasan pasien adalah adanya keluhan yang diterima dari pasien maupun keluaraga tentang pelayanan yang di dapat, adanya tulisan yang terima lewat kotak saran di rumah sakit, adanya Tindakan yang merugikan pasien, dan laporan yang diterima oleh pihak manajemen rumah sakit. Keluhan yang di keluhkan oleh pasien adalah ketidakpuasan pasien Ketika dokter melakukan kunjungan karena dokter kurang memberikan waktu yang cukup dalam memberikan penjelasan tentang 
keadaan pasien, sikap dan perilaku petugas Kesehatan saat melakukan tugasnya seperti komunikasi yang seadanya saat melakukan tindakan yang berhubungan dengan pasien. (Sabarguna, 2016).

Hasil penelitian Ardiansyah mengemukakan bahwa variabel mutu pelayanan kesehatan, penelitian Erwin didapatkan hubungan kualitas pelayanan dengan kepuasan, sedangkan penelitian Wahyuni tidak ada hubungan yang signifikan antara tangible, responsiveness, assurance, reliability dengan kepuasan pasien, namun terdapat hubungan yang signifikan antara emphaty dengan kepuasan pasien di Puskesmas Tepus 1 kabupaten Gunung Kidul (Ardiansyah, 2015, Erwin, 2014 \& Wahyuni, 2015).

Berdasarkan survey awal yang dilakukan di ruang rawat inap 4D Rumah Sakit Grandmed dengan melakukan wawancara terjadap 5 orang pasien dimana terdapat 3 orang pasien yang merasa kurang puas karena perilaku dan cara berkomunikasi perawat dalam memberikan pelayanan kurang baik, pasien merasa tidak cukup waktu untuk berkonsultasi dengan dokter. Berdasarkan data yang didapat diatas maka saya tertarik untuk melakukan penelitian tentang hubungan kualitas pelayanan perawat dengan kepuasan pasien di ruang rawat inap Rumah Sakit Grandmed.

\section{METODE PENELITIAN}

Penelitian ini dilaksanakan di ruang rawat inap Ns 4D Rumah Sakit Grandmed Lubuk Pakam, sampel yang diambil adalah adalah seluruh pasien rawat inap di ruang Ns 4D yaitu 27 orang. Instrumen yang digunakan adalah dengan menggunaakan Kuesioner. Menggunakan menggunakan uji ChiSquare dengan derajat kepercayaan sebesar 95\%. Teknik pengumpulan data yaitu melakukan wawancara langsung kepada responden berpedoman pada kuesioner mengenai Kualitas Pelayanan Perawat Dengan Kepuasan Pasien Di Ruang Rawat Inap.

\section{HASIL}

Tabel 1 menunjukkan bahwa variabel responden memiliki kualitas pelayanan perawat baik sebanyak 16 orang $(59,3 \%)$.

Tabel 1 Kualitas Pelayanan Perawat Di Ruang Rawat Inap 4D Rumah Sakit Grandmed.

\begin{tabular}{ccc}
\hline Kategori & $\begin{array}{c}\text { Jumlah } \\
(\mathbf{n})\end{array}$ & $\begin{array}{c}\text { Persentase } \\
\mathbf{( \% )}\end{array}$ \\
\hline 1. Baik & 16 & 59,3 \\
2. $\begin{array}{c}\text { Tidak } \\
\text { baik }\end{array}$ & 11 & 40,7 \\
\hline Total & 27 & 100.0 \\
\hline
\end{tabular}

Tabel 2 menunjukan responden yang menyatakan pasien puas sebanyak 17 orang $(63,0 \%)$.

Tabel 2 Kualitas Pelayanan Perawat Di Ruang Rawat Inap 4D Rumah Sakit Grandmed.

\begin{tabular}{ccc}
\hline Kategori & $\begin{array}{c}\text { Jumlah } \\
(\mathbf{n})\end{array}$ & $\begin{array}{c}\text { Persentase } \\
(\mathbf{\%})\end{array}$ \\
\hline 1. Puas & 17 & 63,0 \\
2. Tidak & 10 & 37,0 \\
puas & & \\
\hline \multicolumn{1}{c}{ Total } & 27 & 100.0 \\
\hline
\end{tabular}

Tabel 3 Hubungan Kualitas Pelayanan Perawat Dengan Kepuasan Pasien Di Ruang Rawat Inap 4D Rumah Sakit Grandmed 


\begin{tabular}{|c|c|c|c|c|c|c|c|}
\hline \multirow{4}{*}{$\begin{array}{l}\text { Kualit } \\
\text { as } \\
\text { pelaya } \\
\text { nan } \\
\text { peraw } \\
\text { at }\end{array}$} & \multicolumn{6}{|c|}{ Kepuasan Pasien } & \\
\hline & & & & & \multicolumn{2}{|c|}{ Total } & $\begin{array}{c}V \\
\text { al }\end{array}$ \\
\hline & \multicolumn{2}{|c|}{ Puas } & \multicolumn{2}{|c|}{$\begin{array}{l}\text { Tidak } \\
\text { Puas }\end{array}$} & \multirow[b]{2}{*}{$\mathrm{n}$} & \multirow[b]{2}{*}{$\%$} & \\
\hline & $\mathrm{n}$ & $\%$ & $\mathrm{n}$ & $\%$ & & & \\
\hline Baik & $\begin{array}{l}1 \\
5\end{array}$ & $\begin{array}{c}55, \\
6\end{array}$ & 1 & 3,7 & 6 & $\begin{array}{l}59, \\
3\end{array}$ & 0. \\
\hline $\begin{array}{c}\text { Tidak } \\
\text { Baik } \\
\text { Total }\end{array}$ & $\begin{array}{l}2 \\
1 \\
7\end{array}$ & $\begin{array}{l}7,4 \\
63, \\
0\end{array}$ & $\begin{array}{l}9 \\
1 \\
0\end{array}$ & $\begin{array}{c}33, \\
3 \\
37, \\
0\end{array}$ & $\begin{array}{l}1 \\
1 \\
2 \\
7\end{array}$ & $\begin{array}{l}40 \\
7 \\
10 \\
0,0\end{array}$ & $\begin{array}{l}0 \\
2 \\
1\end{array}$ \\
\hline
\end{tabular}

Berdasarkan uji statistik didapatkan kualitas pelayanan perawat baik dan puas sebesar $55,6 \%$ dan yang menyatakan kualitas pelayanan perawat baik serta tidak puas sebesar 3,7\%. Responden yang menyatakan kualitas perawat tidak baik dan puas sebesar $7,4 \%$ dan responden yang menyatakan kualitas pelayanan perawat tidak baik serta tidak puas sebesar $33,3 \%$. Hasil uji statistik chi square diperoleh nilai $p=0,021$ maka dapat disimpulkan bahwa ada hubungan kualitas pelayanan perawat dengan kepuasan di ruang rawat inap Rumah Sakit Grandmed

\section{PEMBAHASAN}

\section{Kualitas Pelayanan Perawat Di Ruang Rawat Inap 4D Rumah Sakit Grandmed}

Hasil penelitian menunjukkan bahwa variabel responden yang menyatakan kualitas pelayanan perawat baik sebanyak 16 orang $(59,3 \%)$ dan kualitas pelayanan tidak baik sebanyak 11 orang $(40,7 \%)$. Hal ini menunjukkan bahwa kualitas pelayanan yang di berikan oleh perawatan merupaka suatu wujud dari sikap profesional yang dapat memberikan rasa nyaman dan sikap melindungi kepada pasien yang sedang mendapatkan perawatan di rumah sakit dengan proses penyembuhan, dimana sikap merupakan sebuah media dalam memberikan pelayanan dan dan dapat memberikan rasa nyaman dan puas terhadap diri sendiri maupun orang lain (Rangkuti, 2015 \& Aditama 2016).

Kualitas pelayanan keperawatan terdiri dari sejumlah keistimewaan seperti keistimewaan langsung dan keistimewaan atraktif yang dapat memenuhi harapan dan kepuasan pasien tersebut (Sedarmayanti, 2015).

Kualitas pelayanan yang dimaksud terdiri dari ketepatan waktu dalam memberikan pelayanan seperti waktu tunggu dan proses, ketepatan pelayanan, tanggung jawab terhadap penanganan keluhan pasien, ruangan tempat pelayanan, tempat parkir, lainlain (Herlambang, 2016 \& Allo 2017).

Kualitas pelayanan dapat berjalan dengan baik apabila didukung oleh pemberi layanan keperawatan harus tersedia di tempat, dapat menjalankan tugas dengan baik, mendokumentasikan setuiap yang di kerjakan dan dapat mempertanggungkawabkan kegiatan dan berkelanjutan, disamping itu etika dan sopan santun saat membrikan pelayanan kepada pasien untuk mendukung kesembuhan (American health insurers dalam Triwibowo, 2016).

\section{Kepuasan Pasien Di Ruang Rawat Inap 4D Rumah Sakit Grandmed}

Kepuasan pasien dapat dilihat dari seluruh komponen atau dimensi dimensi kualitas pelayanan seperti, ketanggapan, kehandalan, jaminan, empati dan bukti langsung. Hasil penelitian didapatkan pasien puas sebanyak $17(63,0 \%)$ dan pasien tidak puas sebanyak 10 orang $(37,0 \%)$ dimana dapat di artikan bahwa kepuasan pasien memiliki nilai yang baik. Hal ini sejalan dengan penelitian Solikhah dimana kepuasan pasien terhadap kualitas pelayanan perawat yaitu sebesar $82,5 \%$. Kepuasan pasien dapat diukur dari kualitas pelayanan di rumah sakit. Kualitas pelayanan 
perawat dapat memberikan kepuasan kepada pasien yang merasa kurang pus terhadap pelayanan yang di dapat, sehingga kepuasan yang baik dapat dipertahankan maupun ditingkatkan agar menjadi lebih baik sehingga kepuasan pasien rawat inap $\geq 90 \%$. (Solikhah, 2016 \& Sedarmayanti, 2015)

Kepuasan pasien adalah suatu perasaan yang dirasakan oleh pasien sebagai akibat dari hasil pelayanan keperawatan yang diterima oleh pasien dan dapat membandingkat apa yang dirasakan. Kepuasan dapat di rasakan saat pasien datang dan meninggalkan rumah sakit. Pelayanan dibentuk berdasarkan lima prinsip Service Quality yaitu kecepatan, ketepatan, keamanan, keramahan dankenyamanan layanan Kepuasan pasien dapat nilai secara subyektif dimana penilaian tersebut yang didasari oleh pengalaman masa lalu, pendidikan, situasi psikis dan lingkungan pada saat itu (Pohan, 2016 \& Sabarguna, 2016).

\section{Hubungan Kualitas Pelayanan Perawat Dengan Kepuasan Di Ruang Rawat Inap 4D Rumah Sakit Grandmed}

Hasil Penelitian yang didapat yaitu kualitas perawat baik dan puas sebesar $55,5 \%$ dan kualitas pelayanan perawat baik serta tidak puas sebesar 3,7\%. Responden yang menyatakan kualitas perawat tidak baik dan puas sebesar $7,4 \%$ dan responden yang menyatakan kualitas pelayanan perawat tidak baik serta tidak puas sebesar 33,3\%. Hasil Uji Statistik Chi Square diperoleh nilai $P=0,021$ sehingga dapat disimpulkan bahwa ada hubungan kualitas pelayanan perawat dengan kepuasan di ruang rawat inap 4D Rumah Sakit Grandmed.

Dari hasil tersebut diatas dapat disimpulkan bahwa semakin tinggi kualitas pelayanan keperawatan maka akan semakin tinggi kepuasan pasien rawat inap 4D di Rumah Sakit Grandmed. Hasil Penelitian tersebut Sesuai Dengan Penelitian yang dilakukan Ardiansyah, dimana Kualitas Pelayanan yang diberikan pada paseien didapatnkan 159 pasien (83\%) sangat baik dan 33 pasien (17\%) menyatakan baik, sedangkan hasil dari penelitian kepuasan pasien rawat inap diperoleh 79 pasien $(41 \%)$ sangat puas dan 19 pasien $(10 \%)$ cukup puas (Ardiansyah, 2015)

Menurut Undang - undang No 44 tahun 2009 menyatakan bahwa Rumah Sakit merupakan tempat Pelayanan Kesehatan yang diberikan secara perorangan yang diberikan secara paripurna yang menyediakan pelayanan rawat inap, rawat jalan, dan gawat darurat. Rumah sakit sebagai bentuk organisasi pelayanan kesehatan yang memberikan pelayanan kesehatan secara komprehensif seperti: promotif, preventif, kuratif dan rehabilitatif bagi seluruh lapisan masyarakat. Untuk menjaga dan meningkatkan mutu pelayanan, maka sangat penting memberikan perhatian khusus kepada pelayanan keperawatan karena salah satu cara menigkatkan mutu rumah sakit adalah pelayanan keperawatan. (UUD No 44, 2009 \& Depkes RI, 1994 Dalam Hidayah, 2014).

Kualitas Layanan merupakan bentuk aktualisasi pelayanan yang dapat memuaskan pelanggan atau pasien yang menerima pelayanan yang terdiri dari lima tanggap (responsiveness), membutuhkan adanya jaminan (asurance), menunjukan bukti fisik (tangible), menunjukan empati (empathy), dan yang memberikan pelayanan sesuai dengan keaandalan (reliability) dengan konsekuensi untuk memuaskan pasien dalam menerima pelayanan. Kualitas pelayanan tersebut dapat dijadikan sebagai satu faktor penentu dari pelayanan kesehatan karena 
keperawatan merupakan satu profesi dengan jumlah terbanyak, paling depan dan terdekat dengan pasien dan keluarganya (Nursalam, 2016 \& Budiastuti 2016)

Kepuasan pasien sangat penting bagi sebuah rumah sakit karena kepuasan pasien merupakan satu modal untuk meningkatkan jumlah kunjungan pasien ke rumah sakit. Dimana yang di harapkan adalah apabila pasien merasa puas dengan pelayanna yang di berikan maka pasien akan dating berkunjung Kembali ke rumah sakit dan mengajak mengajak orang lain untuk menggunakan fasilitas pelayanan kesehatan yang sama, disamping itu pasien juga akan melakukan promosi secara tidak langsung kepada keluarga dan masyarakat sekitar sehingga akan memberikan dampak yang baik kepda rumah sakit. Dengan demikian subsidi silang untuk meningkatkan kualitas pelayanan maupun imbalan yang di terima oleh petugas Kesehatan akan meningkat dan hal ini dapat meningkatkan motivasi kerja untuk lebih baik lagi dalam memberikan pelayanan yang prima kepada pasien dan apabila pasien tersebut membutuhkan pelayanan kesehatan Kembali maka akan Kembali ke palyanan Kesehatan tersebut (Nursalam, 2016).

\section{KESIMPULAN DAN SARAN}

\section{KESIMPULAN}

1. Dari 27 sampel penelitian maka yang memiliki kualitas pelayanan perawat baik 16 orang $(59,3 \%)$ dan kualitas pelayanan tidak baik 11 orang $(40,7 \%)$.

2. Dari 27 sampel, pasien yang menyatakan puas sebanyak 17 orang $(63,0 \%)$ dan yang tidak puas sebanyak 10 orang $(37,0 \%)$.

3. Hasil uji statistik chi square diperoleh nilai $p=0,021$ maka dapat disimpulkan bahwa ada hubungan kualitas pelayanan perawat dengan kepuasan di ruang rawat inap 4D Rumah Sakit Grandmed

\section{SARAN}

1. Bagi Rumah Sakit Grandmed Lubuk Pakam

Rumah sakit agar dapat mempertahankan dan meningkatkan kualitas pelayanan keperawatan dengan memeperhatikan segala unsur unur yang terlibat dalam pelayana keperawatan di rumah sakit.

\section{Bagi Perawat}

Perawat dapat menerapkan hasil penelitian ini dan di jadikan sebagai bahan pertimbangan untuk meningkatkan pelayanan keeprawatan di rumah sakit buhan hanya di ruang rawat inap 4D namun ke seluruh ruang rawat inap di Rumah Sakit Grangmed Lubuk Pakam.

\section{Bagi Institusi Pendidikan}

Penelitian ini dapat menjadi sumber bacaan di perpustakaan Institut Kesehatan Medistra Lubuk Pakam sekaligus sebagai bahan ajar bagi dosen sebagai bahan pergandingan dengn hasil penelitian yang lainnya.

\section{Bagi Peneliti Selanjutnya}

Penelitian ini dapat di teliti Kembali dengan jumlah sampel yang lebih besar dan jumlah ruangan atau rumah rumah sakit yang lebih banyak agar dapat melihat lebih luas tentang pengaruh pelayanan keperawatan terhadap kepuasan pasien. 


\section{DAFTAR PUSTAKA}

Aditama, T. Y. (2016). MANAJEMEN ADMINISTRASI RUMAH SAKIT. Jakarta: Ui Press.

Allo, I.L., Darmawansyah \& Hamzah, A., (2017). STUDI KUALITAS PELAYANAN KESEHATAN BAGI PASIEN RAWAT INAP PESERTA ASURANSI KESEHATAN DI RUMAH SAKIT ELIM RANTEPAO TAHUN 2013. Universitas Hasanuddin Makasar.

Ardiansyah, F. (2015). ANALISIS FAKTOR-FAKTOR YANG BERHUBUNGAN DENGAN KEPUASAN PASIEN PESERTA JKN TENTANG PELAYANAN DI INSTANSI RAWAT INAP RSUD DR. M. YUNUS BENGKULU. Fakultas Keperawatan Universitas Andalas. Tesis

Barata. (2015). PELAYANAN PRIMA. Jakarta: Lembaga Administrasi Negeri RI

Budiastuti. (2016). KEPUASAN PASIEN TERHADAP PELAYANAN RUMAH SAKIT. Jakarta: Trans Info Media.

Irmawati., Kurniawati. (2017). PENGARUH KUALITAS LAYANAN KESEHATAN TERHADAP KEPUTUSAN PASIEN BEROBAT DI RSUD MOEWARDI JEBRES. Benefit Jurnal Manajemen Dan Bisnis Vol: 15

Kotler, (2015). PERSEPSI TERHADAP KEPUASAN PASIEN. Jakarta: Egc Kemenkes. (2016). STANDAR PELAYANAN KEPERAWATAN DI RUMAH SAKIT. JAKARTA: Kementrian Kesehatan RI

Latupono. (2017). HUBUNGAN PELAYANAN DAN KEPUASAN PASIEN RAWAT JALAN DI RSUD MASOHI TAHUN 2014. Jst Kesehatan.Januari 2015.Vol. 5 No. 1.
Nursalam. (2016). MANAJEMEN KEPERAWATAN APLIKASI DALAM PRAKTIK KEPERAWATAN PROFESIONAL. Jakarta: Salemba Medika.

Pohan, Imbalo S. (2016). JAMINAN MUTU LAYANAN KESEHATAN: DASAR - DASAR PENGERTIAN DAN PENERAPAN. Jakarta: Egc

Rangkuti, F., (2015). MENGUKUR KEPUASAN PELANGGAN. Gramedia Pustaka Utama

Sabarguna, B. (2016). QUALITY ASSURANCE PELAYANAN RUMAH SAKIT. Jakarta: Edisi Revisi, Sagung Seto.

Salimah, S. (2016). TRAINING NEED ANALYSIS (TNA) DI RUMAH SAKIT.

Http://Indosdm.Com/TrainingNeed-Analysis-Tna-Di-RumahSakit

Sari, A. I. (2017). TINGKAT KEPUASAN KONSUMEN PADA MUTU PELAYANAN RUMAH MAKAN (STUDI PADA RM. JAWA DELI, RM. PUTRI MINANG DAN RM. TAK BERNAMA DI KAMPUNG SUSUK, KAMPUS USU-MEDAN). Jurnal Keuangan \& Bisnis Program Studi Magister Manajemen Sekolah Tinggi Ilmu Ekonomi Harapan 4.2: 148-159.

Sedarmayanti. (2015). SUMBER DAYA MANUSIA DAN PRODUKTIVITAS KERJA. Bandung: $\mathrm{CV}$ Mandar Maju.

Wahyuni, Dwi, Liena Sofiana. (2015). HUBUNGAN ANTARA KUALITAS PELAYANAN KESEHATAN DENGAN KEPUASAN PASIEN DI PUSKESMAS TEPUS I KABUPATEN GUNUNG KIDUL YOGYAKARTA. Jurnal Medika Respati: 2015;X(2). 